\title{
Effects of Aluminum Powder on Ignition Performance of RDX, HMX, and CL-20 Explosives
}

\author{
Xiaoxiang Mao, Longfei Jiang $(\mathbb{D}$, Chenguang Zhu $(\mathbb{D}$, and Xiaoming Wang \\ Nanjing University of Science and Technology, Nanjing 210094, China \\ Correspondence should be addressed to Chenguang Zhu; zhuchen1967@gmail.com
}

Received 3 May 2017; Revised 4 August 2017; Accepted 26 September 2017; Published 17 January 2018

Academic Editor: Fernando Lusquiños

Copyright ( 92018 Xiaoxiang Mao et al. This is an open access article distributed under the Creative Commons Attribution License, which permits unrestricted use, distribution, and reproduction in any medium, provided the original work is properly cited.

\begin{abstract}
As a kind of high explosives, aluminized explosive cannot release the energy maximumly, which is a key problem. Using DTA-TG equipment, the ignition performance of three kinds of aluminized explosives (RDX, HMX, and CL-20) with different mass percentages of aluminum powder $(0 \%, 10 \mathrm{wt} . \%, 20 \mathrm{wt} . \%$, and $30 \mathrm{wt} . \%)$ was investigated. The results showed that the energy release of the HMX/Al composite explosive with $10 \mathrm{wt} . \%, 20 \mathrm{wt} . \%$, and $30 \mathrm{wt} . \%$ aluminum powder was only equivalent to $80 \%, 65 \%$, and $36 \%$ of pure HMX, respectively. It was similar to RDX/Al and CL-20/Al composite explosives, except the CL-20/Al mixture with $10 \%$ aluminum powder. Rather than participating in the ignition and combustion, the aluminum powder does effect the complete reaction of RDX, HMX, and CL-20 in the initial stage of ignition or in the lower temperature area of the boundary.
\end{abstract}

\section{Introduction}

Aluminum powder can be incorporated into explosives to raise the reaction temperature, enhance the heat of detonation, increase bubble energies in underwater weapons, improve air blast, and create an incendiary effect [1]. Therefore, the aluminized explosive is usually called high explosive and has attracted much attention. Vadhe et al. [2] summarized the development trend of aluminized explosives and considered adequately their low sensitivity and good mechanical properties. Tao et al. [3] studied the early dynamic characteristics of $\mathrm{Al}$ powder which was heated after the detonation of aluminized explosives. Stromsoe et al. [4] proposed that both the bubble energy and the shock wave energy of aluminized explosives were higher than those of pure explosives in a certain range of $\mathrm{Al}$ content. Peng et al. [5] found that the size, the activity, and the shape of $\mathrm{Al}$ powder could significantly affect the energy level of aluminized explosives. Hwang et al. [6] reported the application characteristics of nickel-coated $\mathrm{Al}$ powder in the explosives, whose results showed that nickel was able to reduce the ignition temperature of $\mathrm{Al}$ powder and improved the impulse, the pressure, and the temperature field. However, the above researches highlight a problem that aluminized explosives show nonideal behavior. The anticipated energy of aluminized explosives is very hard to be utilized fully [7-9]. The combustion of Al powder is incomplete in the actual explosion process, resulting in the incomplete release of energy. Thus, Gogulya et al. [10] tried to promote the reaction of $\mathrm{Al}$ powder using Teflon and Viton.

The purpose of the present work is to investigate the effect of $\mathrm{Al}$ powder on the ignition property based on thermogravimetric analysis and differential thermal analysis (TG-DTA). The samples are cyclotrimethylene trinitramine (RDX), cyclotetramethylenetetranitramine (HMX), and hexanitrohexaazaisowurtzitane (CL-20), with different mass percentages of $\mathrm{Al}$ powder. On this basis, the underlying reason is explored that aluminized explosives showed nonideal behavior in the process of practical application.

\section{Experimental}

\subsection{Reagents and Instruments}

2.1.1. Reagents. Al powder ( 350 mesh, particle size $<40 \mu \mathrm{m}$ ) was obtained from Tangshan Weihao Magnesium Powder Co., Ltd. RDX (80 mesh), HMX (80 mesh), and CL-20 (80 mesh) were obtained from Qingyang Chemical Co., Ltd. 


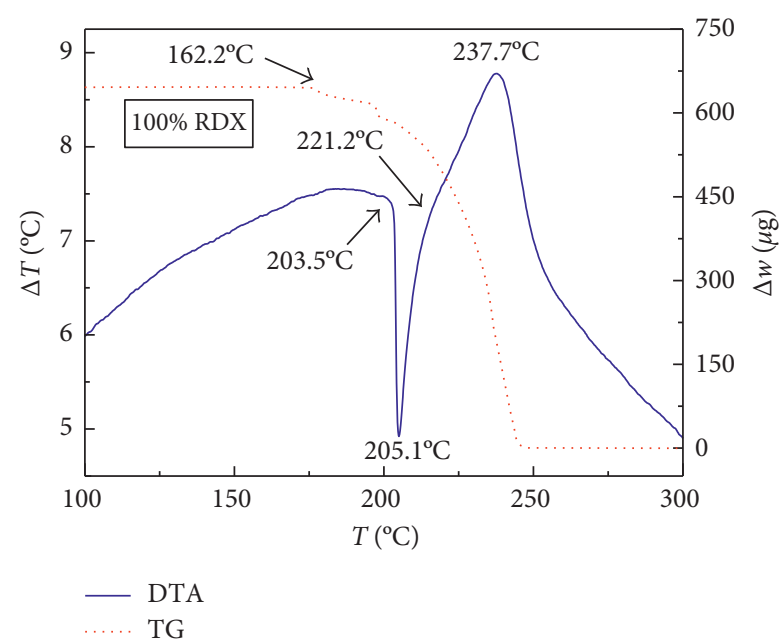

(a)

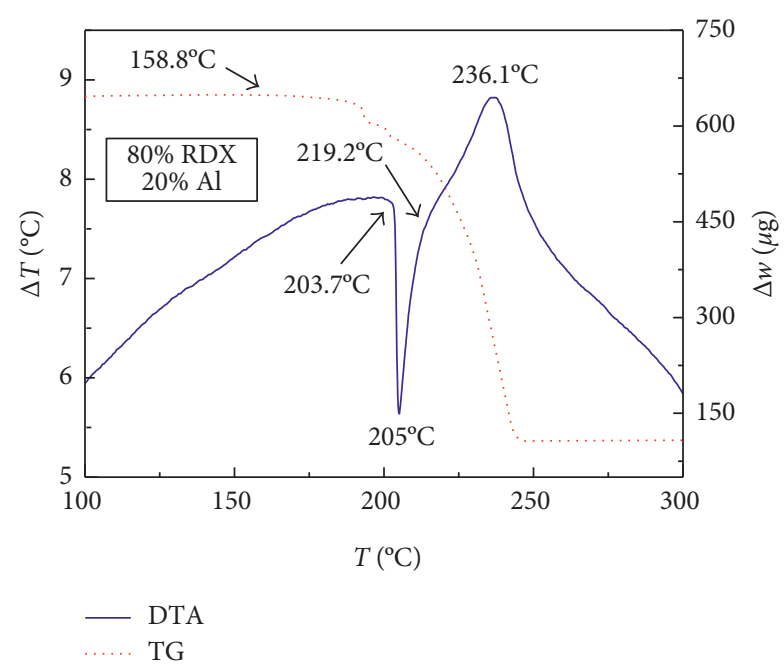

(c)

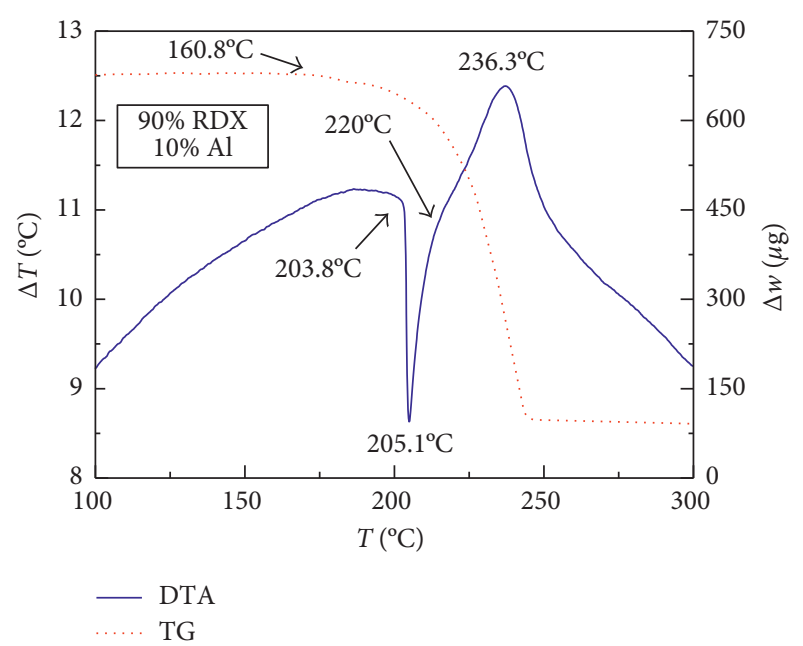

(b)

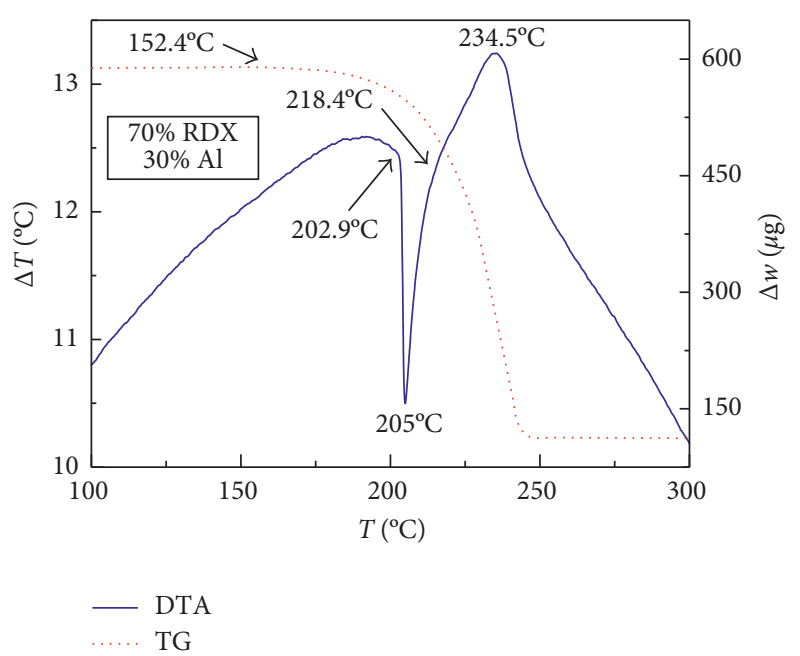

(d)

Figure 1: TG-DTA curves of RDX/Al. (a) Pure RDX; (b) RDX 90 wt.\% and Al 10 wt.\%; (c) RDX 80 wt.\% and Al 20 wt.\%; (d) RDX 70 wt.\% and $\mathrm{Al} 30$ wt.\%.

2.1.2. Instrument. DTA-50-type differential thermal analyzer (NETZSCH-Gerätebau GmbH) and Hot Disk TPS 2500S thermal conductivity meter (Swedish Kaigenasi Company) were used.

2.2. Sample Preparation. Mix different mass percentages of Al powder (0\%, $10 \mathrm{wt} . \%, 20 \mathrm{wt} . \%$, and $30 \mathrm{wt} . \%)$, respectively, with RDX, HMX, and CL-20 uniformly.

2.3. TG-DTA Parameters. Differential thermal analysis was performed on STA449C high-temperature thermal analyzer. Experimental conditions are as follows: sample weight was $0.5 \mathrm{mg}$, carrier gas was air, gas velocity was $100 \mathrm{~mL} / \mathrm{min}, \mathrm{Al}_{2} \mathrm{O}_{3}$ crucibles, and gradient heating at a constant rate of $10^{\circ} \mathrm{C} / \mathrm{min}$ ranging from normal temperature to $600^{\circ} \mathrm{C}$. The $\alpha-\mathrm{Al}_{2} \mathrm{O}_{3}$ was used as the reference sample to correct the reference instrument, and the crucibles were exposed during the whole process. The equipment was corrected before each test.

\section{Results and Discussion}

3.1. Ignition Temperature. Figures 1-3 show the TG-DTA curves of the three groups of samples, corresponding to the formulations of RDX/Al, $\mathrm{HMX} / \mathrm{Al}$, and CL-20/Al, respectively.

According to the TG-DTA curves, the first strong exothermic peak of the DTA curves generally corresponds to a significant loss of weight in TG curve, which can be extrapolated by ignition temperature (Te). The Te of the three groups of samples is shown in Table 1 based on the results of Figures 1-3. As shown in Table 1, the changes of Te are not obvious after adding different mass percentages of $\mathrm{Al}$ powder, which means that $\mathrm{Al}$ powder does not change the $\mathrm{Te}$ of these three kinds of explosives. 


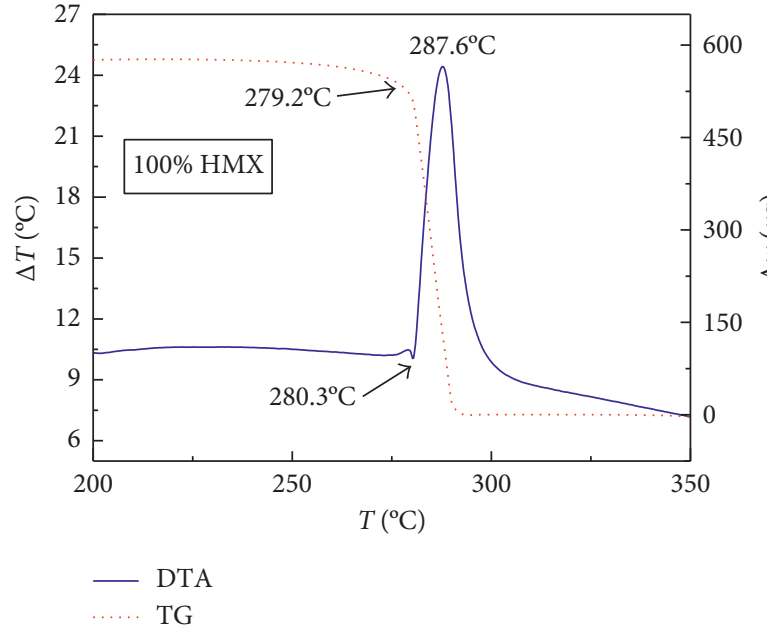

(a)

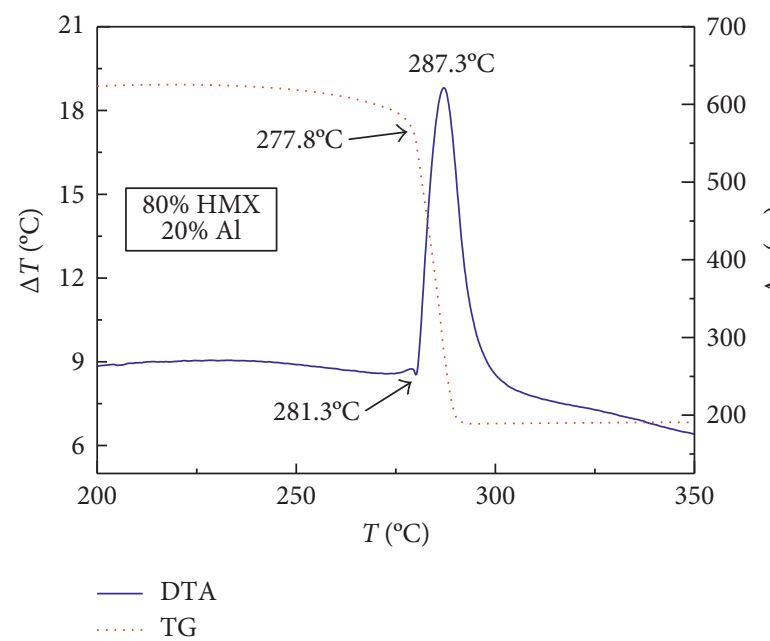

(c)

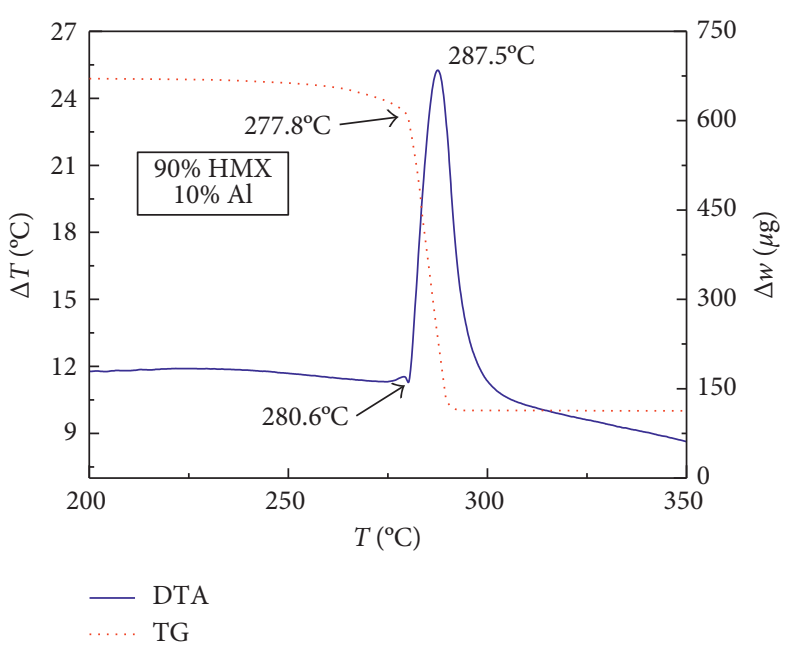

(b)

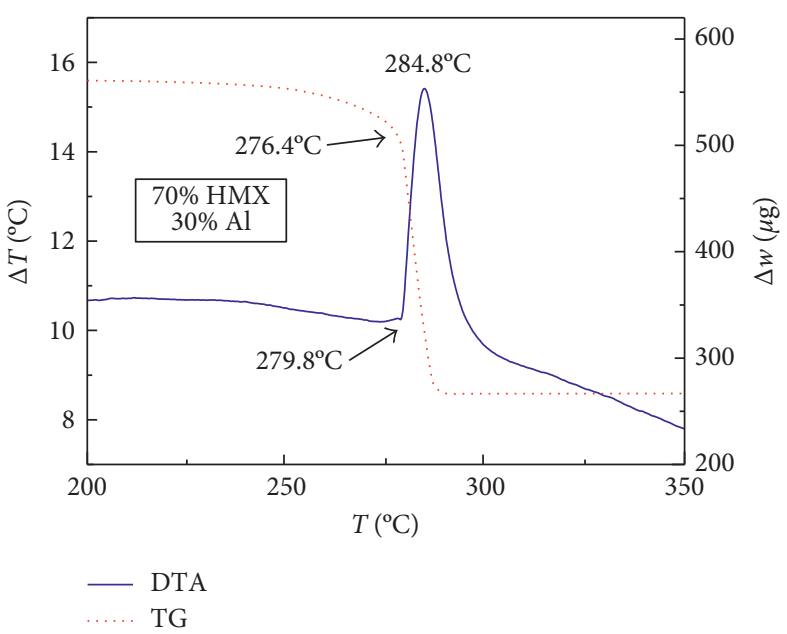

(d)

Figure 2: TG-DTA curves of HMX/Al. (a) Pure HMX; (b) HMX 90 wt.\% and Al 10 wt.\%; (c) HMX 80 wt.\% and Al 20 wt.\%; (d) HMX 70 wt.\% and $\mathrm{Al} 30$ wt.\%.

3.2. Thermal Conductivity. The thermal conductivity tests of samples were carried out after the samples were pressed into flakes. The thermal conductivity of pure $\mathrm{Al}$ and shell steel was measured simultaneously, and the testing values were $226 \mathrm{~W} \cdot \mathrm{m}^{-1} \cdot \mathrm{K}^{-1}$ and $8.25 \mathrm{~W} \cdot \mathrm{m}^{-1} \cdot \mathrm{K}^{-1}$.

The fitting results of testing values are shown in Figure 4, indicating the variation trend of the thermal conductivity with the mass percentage change of $\mathrm{Al}$ powder. We find that the thermal conductivities of different explosives are all improved gradually as the mass percentage of $\mathrm{Al}$ powder increases, originating from the higher thermal conductivities of Al.

3.3. Calculation Formula. The weight of the samples was normalized to directly evaluate the effects of different mass percentages of $\mathrm{Al}$ powder on the energy release of explosives.

\subsubsection{Mass Normalization Formula}

$$
M_{s}=\frac{1000}{n} \times \sum_{i=1}^{n} \frac{M_{i}}{M_{0}}
$$

where $M_{s}$ is the normalized mass, $M_{0}$ is the original mass, $M_{i}$ is the dynamic mass measured by TG-DTA device, $n$ is the number of data points, and 1000 is the reference value.

\subsubsection{Theoretical Exothermic Enthalpy Percentage of} Composite Explosives

$$
\Delta H \%=1+\left(\frac{\Delta H_{\mathrm{Al}}}{\Delta H_{\text {explosive }}}-1\right) \times p
$$

where $\Delta H_{\mathrm{Al}}$ and $\Delta H_{\text {explosive }}$ are the standard exothermic enthalpy of $\mathrm{Al}$ and pure explosives, respectively (Table 2 ) and $p$ is the mass percentage of Al. 


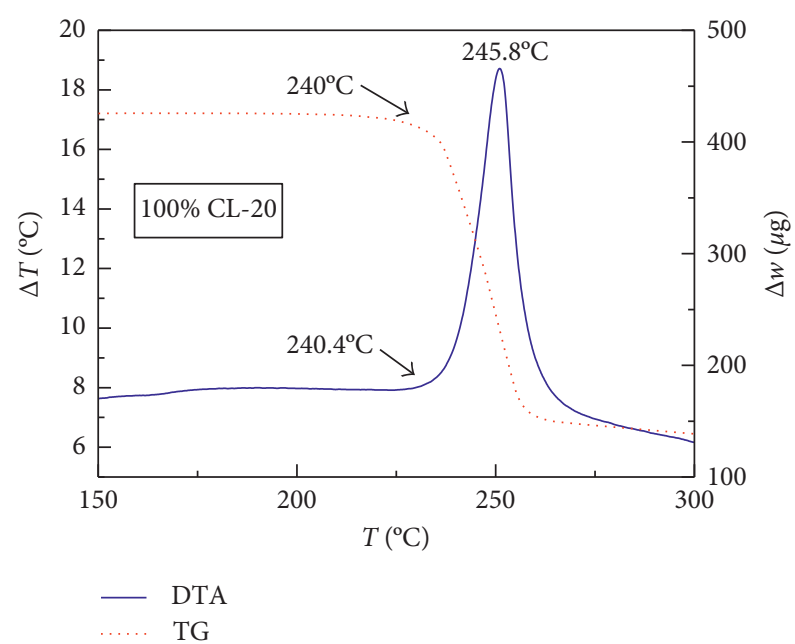

(a)

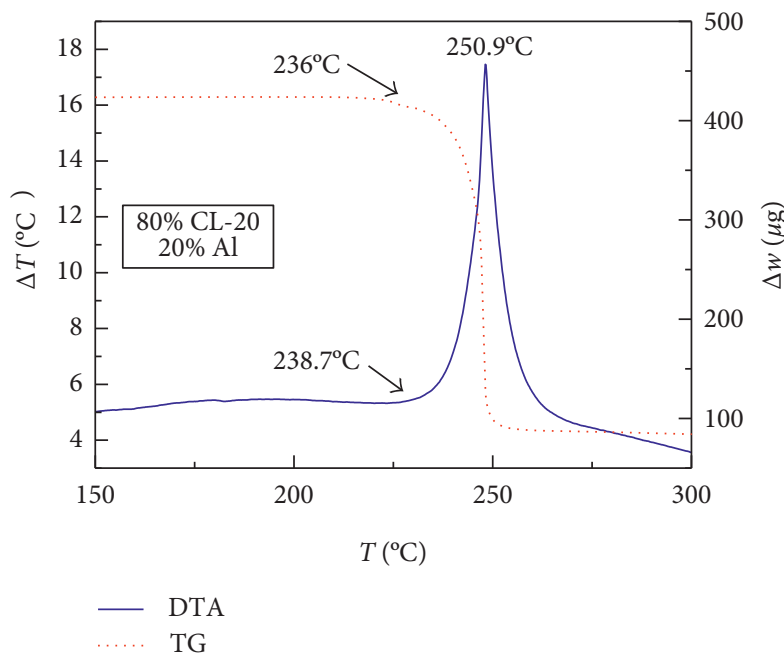

(c)

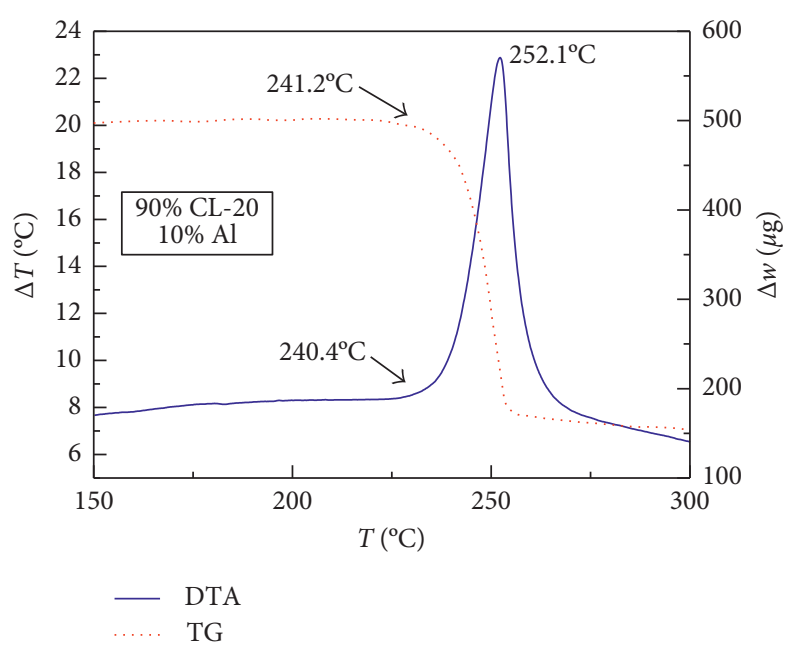

(b)

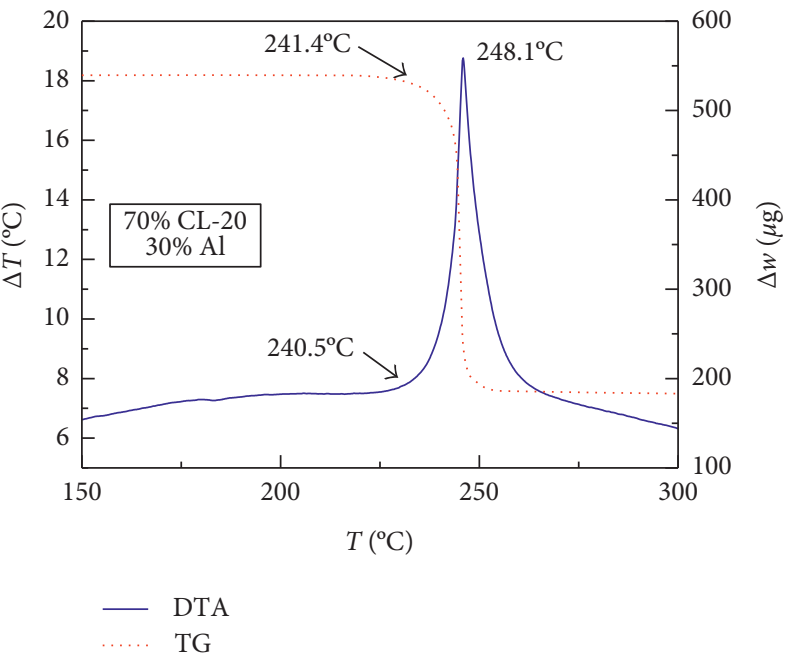

(d)

Figure 3: TG-DTA curves of CL-20/Al. (a) Pure CL-20; (b) CL-20 90 wt.\% and Al 10 wt.\%; (c) CL-20 80 wt.\% and Al 20 wt.\%; (d) CL-20 70 wt.\% and $\mathrm{Al} 30$ wt.\%.

TABLE 1: Ignition temperature of the three groups of samples.

\begin{tabular}{|c|c|c|c|c|}
\hline \multirow{2}{*}{ Sample } & \multicolumn{4}{|c|}{$\mathrm{Te}\left({ }^{\circ} \mathrm{C}\right)$} \\
\hline & $\mathrm{Al}-0 \%$ & Al-10 wt.\% & Al-20 wt.\% & Al-30 wt. $\%$ \\
\hline $\mathrm{RDX} / \mathrm{Al}$ & 205.1 & 205.1 & 205.0 & 205.0 \\
\hline $\mathrm{HMX} / \mathrm{Al}$ & 280.3 & 280.6 & 281.3 & 279.8 \\
\hline CL-20/Al & 240.4 & 240.4 & 238.7 & 241.5 \\
\hline
\end{tabular}

3.4. Ignition Release Energy. After correcting the baseline of curves in Figures 1-3 and normalizing the mass of samples, the results are shown in Figures 5-7. Notably, Figure 5 presents the DTA curves of RDX mixed with different mass percentages of $\mathrm{Al}$ powder, in which the exothermic peaks reduce gradually with the increasing mass percentages of $\mathrm{Al}$ powder. The declining trend of exothermic peaks is more obvious in the DTA curve of HMX/Al shown in Figure 6.
However, CL-20 exhibits different characteristics compared with those of RDX and HMX shown in Figure 7, of which exothermic peaks change irregularly.

Table 3 lists the exothermic enthalpy data $(\Delta H)[11,12]$ of the three groups of samples which can be calculated by integral processing of exothermic peaks in DTA curves.

For comparison, the relative exothermic enthalpy percentage of samples is calculated based on the exothermic 

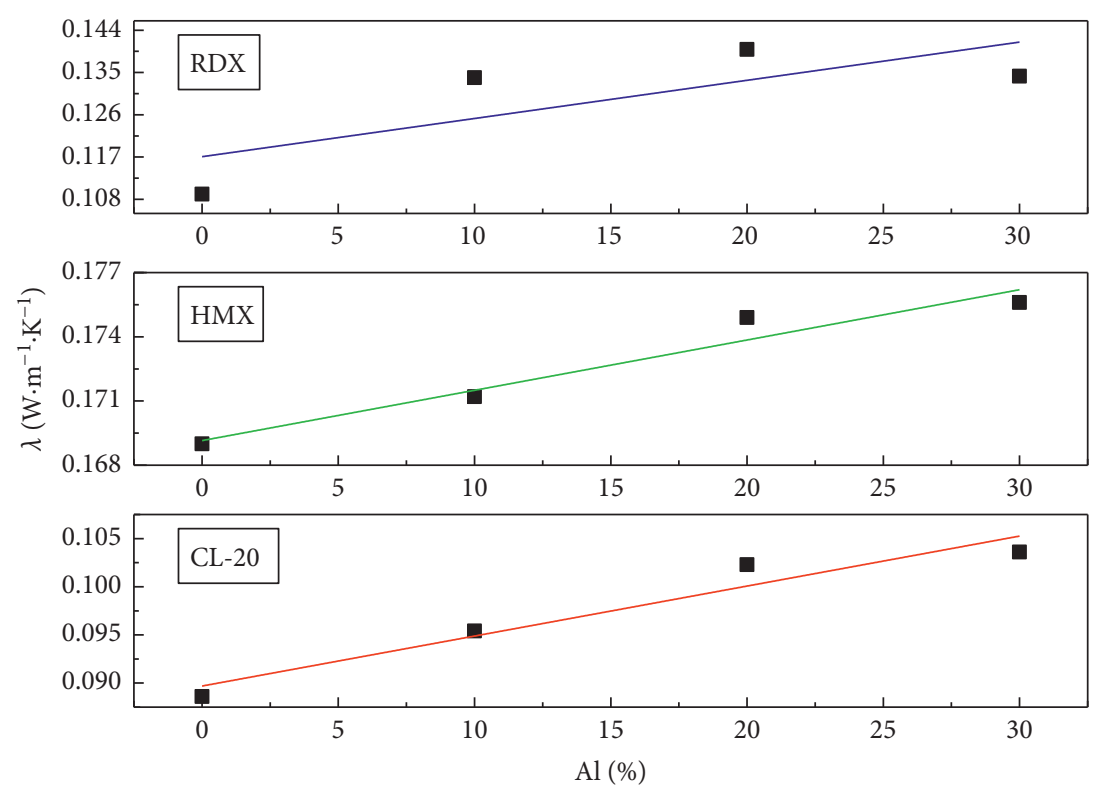

Figure 4: Thermal conductivity of the three groups of samples (testing temperature was $25^{\circ} \mathrm{C}$ ).

TABLE 2: Standard exothermic enthalpy of pure substances.

\begin{tabular}{lc}
\hline Pure substance & $\Delta H\left(\mathrm{~kJ} \cdot \mathrm{kg}^{-1}\right)$ \\
\hline RDX & 5400 \\
HMX & 5673 \\
CL-20 & 7100 \\
Al & $30,222.22$ \\
\hline
\end{tabular}
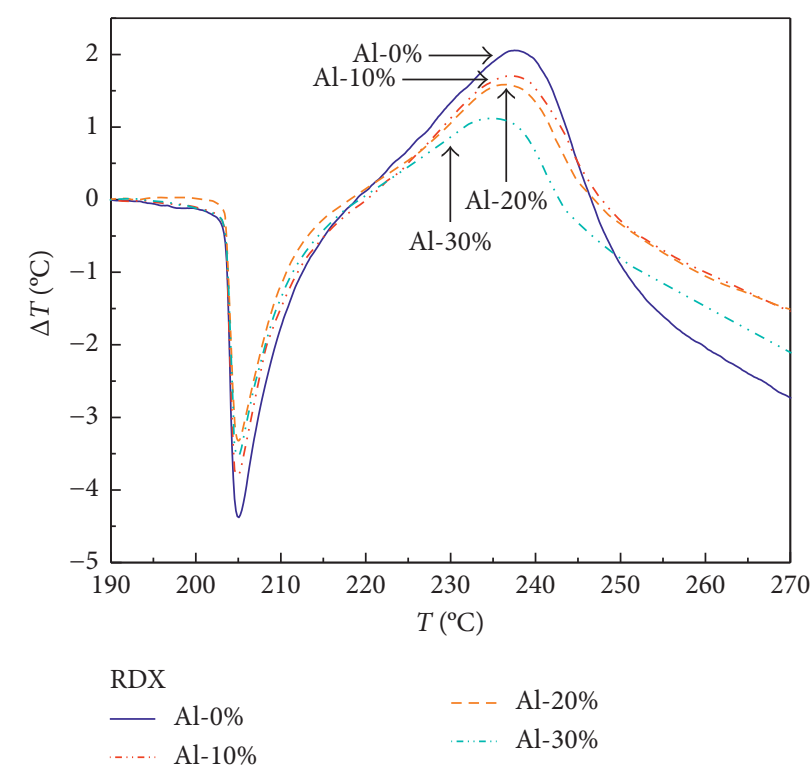

Figure 5: DTA curves of RDX with different mass percentages of $\mathrm{Al}$ powder.

enthalpy of pure explosives listed in Table 4. The data in parentheses are theoretical exothermic enthalpy percentages of composite explosives.
It can be seen from Table 4 that the released energy of the $\mathrm{RDX} / \mathrm{Al}$ composite explosive with $10 \mathrm{wt} \% \mathrm{Al}$ powder (i.e., containing $90 \mathrm{wt} . \% \mathrm{RDX}$ ) is merely $74.4 \%$ of pure $\mathrm{RDX}$, 


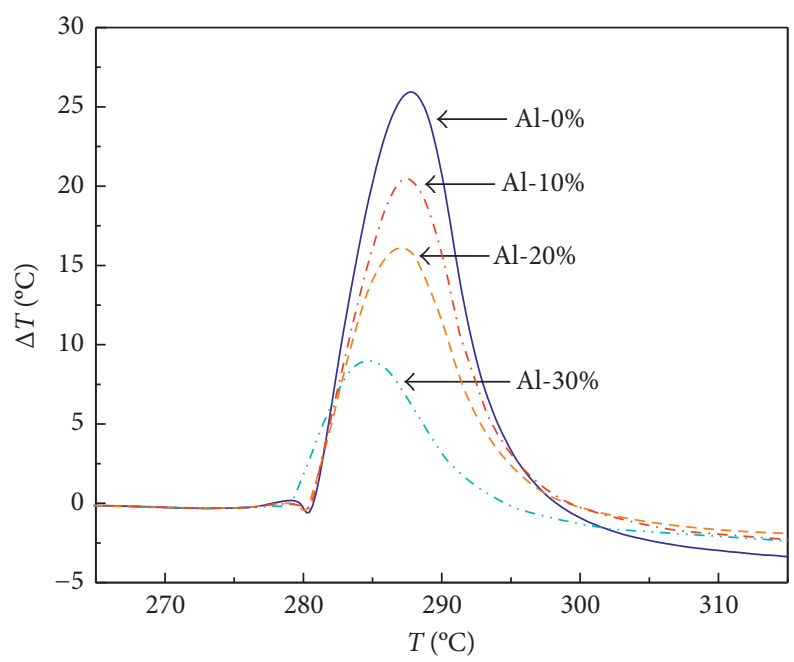

HMX

$\begin{array}{ll}-\mathrm{Al}-0 \% & --\mathrm{Al}-20 \% \\ -\mathrm{Al}-10 \% & \ldots \mathrm{Al}-30 \%\end{array}$

Figure 6: DTA curves of HMX with different mass percentages of Al powder.

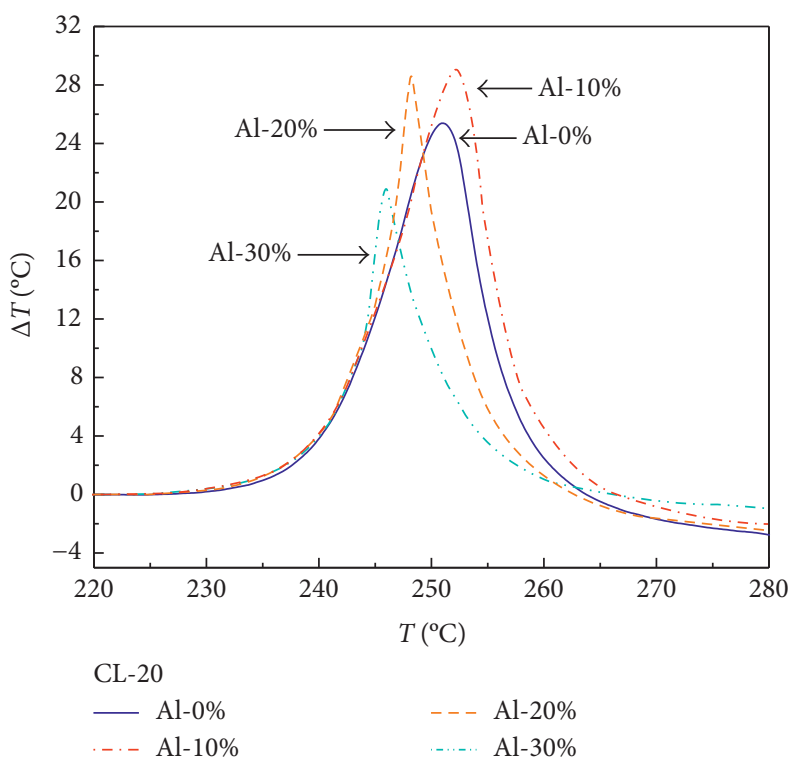

Figure 7: DTA curves of CL-20 with different mass percentages of Al powder.

which means the $\mathrm{Al}$ powder does not react and even block the complete reaction of RDX. The gap between the actual value and the theoretical value widens as the mass percentage of $\mathrm{Al}$ powder increases. The released energy of $\mathrm{RDX} / \mathrm{Al}$ with $20 \mathrm{wt} \% \mathrm{Al}$ is merely $61.5 \%$ of pure RDX, and the value of $\mathrm{RDX} / \mathrm{Al}$ with $30 \mathrm{wt} \% \mathrm{Al}$ is only $40.8 \%$. The $\mathrm{HMX} / \mathrm{Al}$ composite explosive exhibits the same rule as $\mathrm{RDX} / \mathrm{Al}$. The released energy of $\mathrm{HMX} / \mathrm{Al}$ with $10 \mathrm{wt} \% \mathrm{Al}$ is merely $80.3 \%$ of pure HMX, not even reaching $90 \%$, and the values of $\mathrm{HMX} / \mathrm{Al}$ with $20 \mathrm{wt} . \%$ and 30 wt.\% $\mathrm{Al}$ are $64.8 \%$ and $36.1 \%$, respectively. These results illustrate that the $\mathrm{Al}$ powder in $\mathrm{RDX} / \mathrm{Al}$ and $\mathrm{HMX} / \mathrm{Al}$ composite explosives
TABLE 3: Exothermic enthalpy data of the three groups of samples.

\begin{tabular}{lcccc}
\hline \multirow{2}{*}{ Sample } & \multicolumn{4}{c}{$\Delta H\left(\mathrm{uV} \cdot \mathrm{s} \cdot \mathrm{mg}^{-1}\right)$} \\
& Al-0\% & Al-10 wt.\% & Al-20 wt.\% & Al-30 wt.\% \\
\hline RDX/Al & -332.2 & -247.3 & -204.3 & -135.4 \\
HMX/Al & -1483 & -1191 & -960.6 & -535.0 \\
CL-20/Al & -2120 & -2230 & -1684 & -1169 \\
\hline
\end{tabular}

cannot burn at the initial stage of ignition but impact the burning property of explosives around the Al particles.

Unlike RDX and HMX, the released energy of CL-20/Al composite explosive with 10 wt. $\%$ Al powder is $105.2 \%$ of 
TABLE 4: Exothermic enthalpy percentage of the three groups of samples.

\begin{tabular}{lcccc}
\hline Sample & & & & \\
& Al-0\% & Al-10 wt.\% & Al-20 wt.\% & Al-30 wt.\% \\
\hline RDX/Al & $100(100)$ & $74.4(145.97)$ & $61.5(191.93)$ & $40.8(237.9)$ \\
HMX/Al & $100(100)$ & $80.3(143.27)$ & $64.8(186.55)$ & $36.1(229.82)$ \\
CL-20/Al & $100(100)$ & $\mathbf{1 0 5 . 2 ( 1 3 2 . 5 7 )}$ & $79.4(165.13)$ & $55.1(197.7)$ \\
\hline
\end{tabular}

pure CL-20, exceeding 90\% but lower than the theoretical value $(132.57 \%)$, indicating that part of the $\mathrm{Al}$ powder joined the reaction and released energy. However, as the mass percentage of $\mathrm{Al}$ powder increases, the released energy is reduced obviously. The released energy of CL-20/Al with $20 \mathrm{wt} . \%$ and $30 \mathrm{wt} . \% \mathrm{Al}$ is merely equal to $79.4 \%$ and $55.1 \%$ of pure CL-20, respectively, which suggests that part of CL-20 does not react. This may be attributed to the higher thermal conductivity of $\mathrm{Al}$, which makes part of $\mathrm{Al}$ particles dissipate the heat by themselves and CL-20 around them simultaneously, resulting in unachievable reaction temperature condition and the end of the reaction.

The result of this experiment indicates that $\mathrm{Al}$ particles in RDX and HMX cannot react under low-temperature condition or the ignition temperature condition. Due to the high melting point $\left(660.4^{\circ} \mathrm{C}\right)$, boiling point $\left(2467^{\circ} \mathrm{C}\right)$, and low saturated vapor pressure, $\mathrm{Al}$ is difficult to volatilize [13], which makes $\mathrm{Al}$ nonreactive in gaseous form under the lowtemperature condition. Although explosives release energy in the form of high temperature, high pressure, and highspeed detonation, the process could still be regarded as a continuous ignition process. Due to low temperature, the $\mathrm{Al}$ particles far from the explosion core do not react, and at the same time, it dissipates the heat around, which makes incomplete combustion of reactants.

Therefore, to make Al particles and explosives around them combust completely and fast in the microscale, they should be under the high-temperature condition or in the existence of an urge medium such as CL-20 and ammonium perchlorate $[10,12]$. A further study can be carried out to investigate the mechanism of CL-20 promoting the combustion of $\mathrm{Al}$ particles in ignition process.

\section{Conclusions}

This study focuses on the ignition performance of RDX, HMX, and CL-20 with different mass percentages of $\mathrm{Al}$ powder. It is found that only $80 \%, 65 \%$, and $36 \%$ of HMX reacted for the energy release from the HMX/Al composite explosive with $90 \%, 80 \%$, and $70 \%$ HMX, respectively. Moreover, the RDX/Al composite explosive presents even lower energy release. In the initial stage of ignition, aluminum powder can obviously affect the reaction of RDX or HMX in the composite explosives. The experiment found that the energy release of the CL-20/Al composite explosive with $10 \mathrm{wt} . \% \mathrm{Al}$ powder was $5 \%$ higher than that of pure CL-20, which meant part of aluminum powder participated in chemical reactions in the ignition stage. The conclusions are as follows:
(1) There are no obvious effects of $\mathrm{Al}$ powder ( $\leq 30 \mathrm{wt} . \%)$ on the ignition temperature of RDX, HMX, and CL-20.

(2) Al powder blocks the energy release processes of RDX and HMX evidently and may not react at the initial stage of ignition.

(3) The CL-20/Al composite explosive with 10 wt.\% Al powder can release more energy than that of pure CL-20, which may be caused by the energy release of partial Al powder promoted by CL- 20 .

The thermal conductivity of aluminized explosives increases accordingly with the increasing mass percentage of Al powder, which accelerates the heat dissipation. Therefore, part of the explosives in touch with the Al particle is not easy to approach spontaneous reaction temperature compared with the others, resulting in termination of reaction or time difference of energy release on the chemical reaction.

\section{Conflicts of Interest}

The authors declare that they have no conflicts of interest.

\section{Acknowledgments}

This work was supported by the National Science Foundation of China (approval number 51676100).

\section{References}

[1] R. A. Schaefer and S. M. Nicolich, "Development and evaluation of new high blast explosives," in Proceeding of the 36th International Annual Conference of ICT, Karlsrube, Germany, June-July 2005.

[2] P. P. Vadhe, R. B. Pawar, R. K. Sinha, S. N. Asthana, and A. Subhananda Rao, "Cast aluminized explosives (review)," Combustion, Explosion, and Shock Waves, vol. 44, no. 4, pp. 461-477, 2008.

[3] W. C. Tao, C. M. Tarver, J. W. Kury, and D. L. Ornellas, "Understanding composite explosive energetic: 4. Reactive flow modeling of aluminium reaction kinetics using normalized product equation of state," in Proceedings of Tenth Symposium (International) on Detonation, Annapolis, MD, USA, Naval Surface Weapons Center, 1993.

[4] E. Stromsoe and S. Eriksen, "Performance of high explosives in underwater applications. Part 2: aluminized explosives," Propellants, Explosives, Pyrotechnics, vol. 15, no. 2, pp. 52-53, 1990.

[5] J. Peng, W. Chen, H. Su et al., "The effect of aluminum powder upon aluminized explosive underwater detonation 
performance," Journal of Safety and Environment, vol. 4, pp. 177-179, 2004.

[6] J. S. Hwang, C. K. Kim, and J. R. Cho, "Development of new thermobaric explosive composition using nickel coated aluminium powder," in Proceedings of the 38th International Annual Conference of ICT, Karlsruhe, Germany, June 2007.

[7] X. Wang, "Developmental trends in military composite explosive," Chinese Journal of Explosives and Propellants, vol. 34, no. 4, pp. 1-4, 2011.

[8] W. Arnold and E. Rottenkolber, "Thermobaric charges: modelling and testing," in Proceedings of the 38th International Annual Conference of ICT, Karlsruhe, Germany, June 2007.

[9] W. Arnold and E. Rottenkolber, "Combustion of an aluminized explosive in a detonation chamber," in Proceedings of the 39th International Annual Conference of ICT, Karlsruhe, Germany, June 2008.

[10] M. F. Gogulya, M. N. Makhov, M. A. Brazhnikov, and A. Y. Dolgoborodov, "Detonation-like process in Teflon/Albased explosive mixture," in Proceedings of the 40th International Annual Conference of ICT, Karlsruhe, Germany, June 2009.

[11] P. B. Joshi, G. R. Marathe, N. S. S. Murti, V. K. Kaushik, and P. Ramakrishnan, "Reactive synthesis of titanium matrix composite powders," Materials Letters, vol. 56, no. 3, pp. 322-328, 2002.

[12] C. Zhu, H. Wang, and M. Li, "Ignition temperature of magnesium powder and pyrotechnic composition," Journal of Energetic Materials, vol. 32, no. 3, pp. 219-226, 2014.

[13] M. M. Avedesian and H. Baker, Magnesium and Magnesium Alloys, ASM International, Novelty, OH, USA, 1999. 


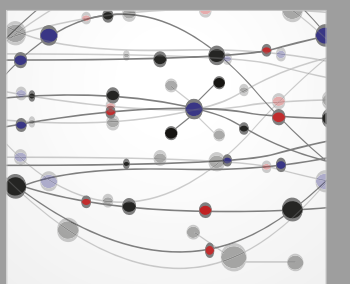

The Scientific World Journal
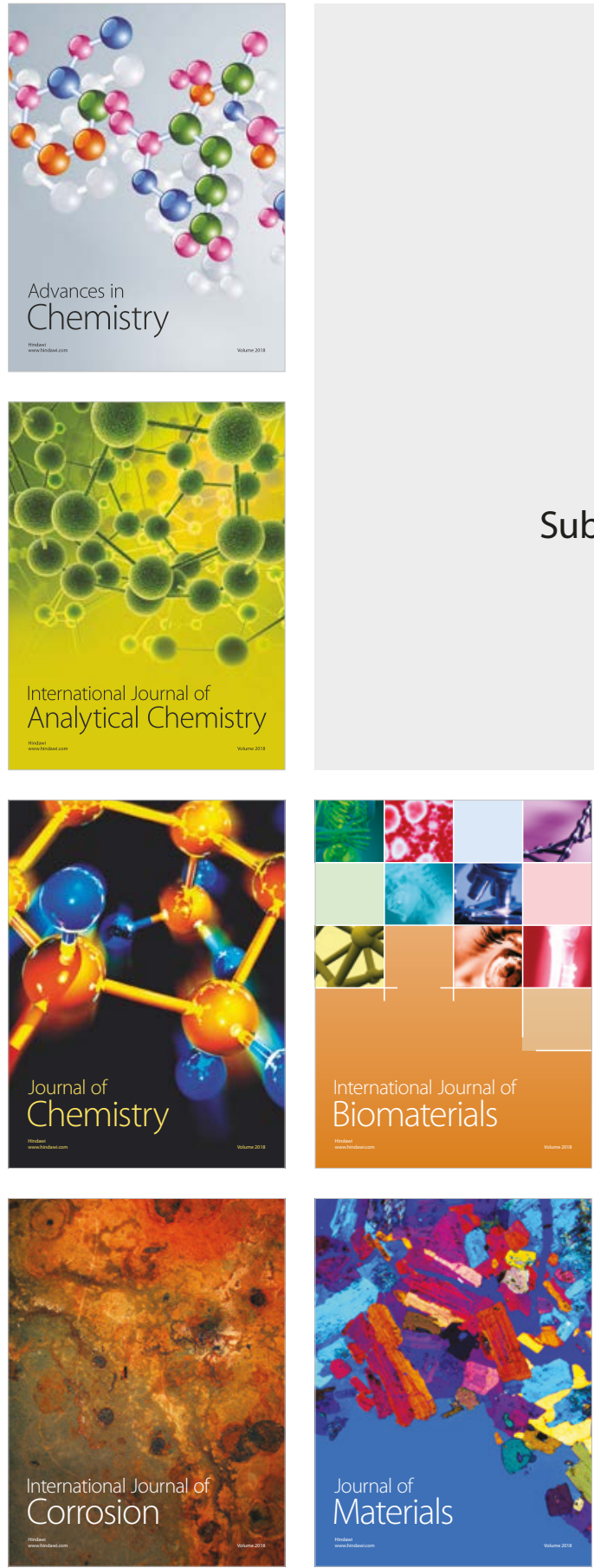

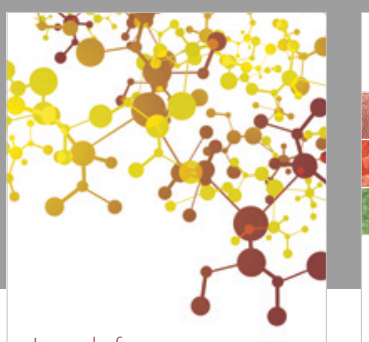

Journal of

Applied Chemistry
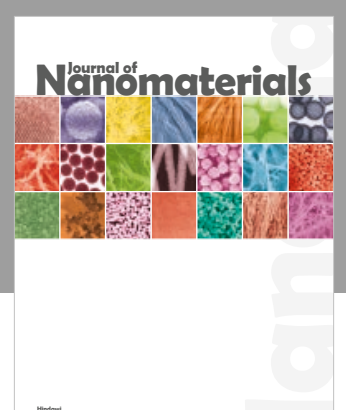

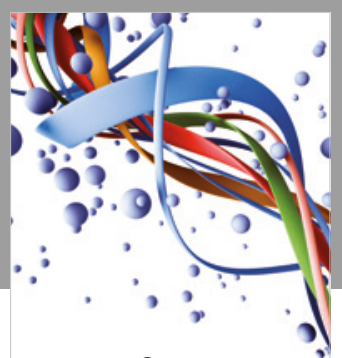

Scientifica

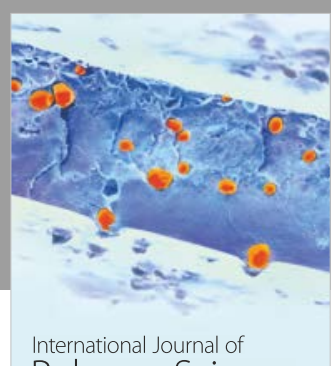

Polymer Science

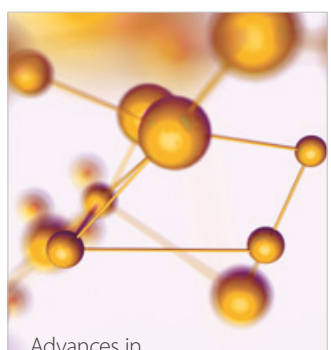

Physical Chemistry
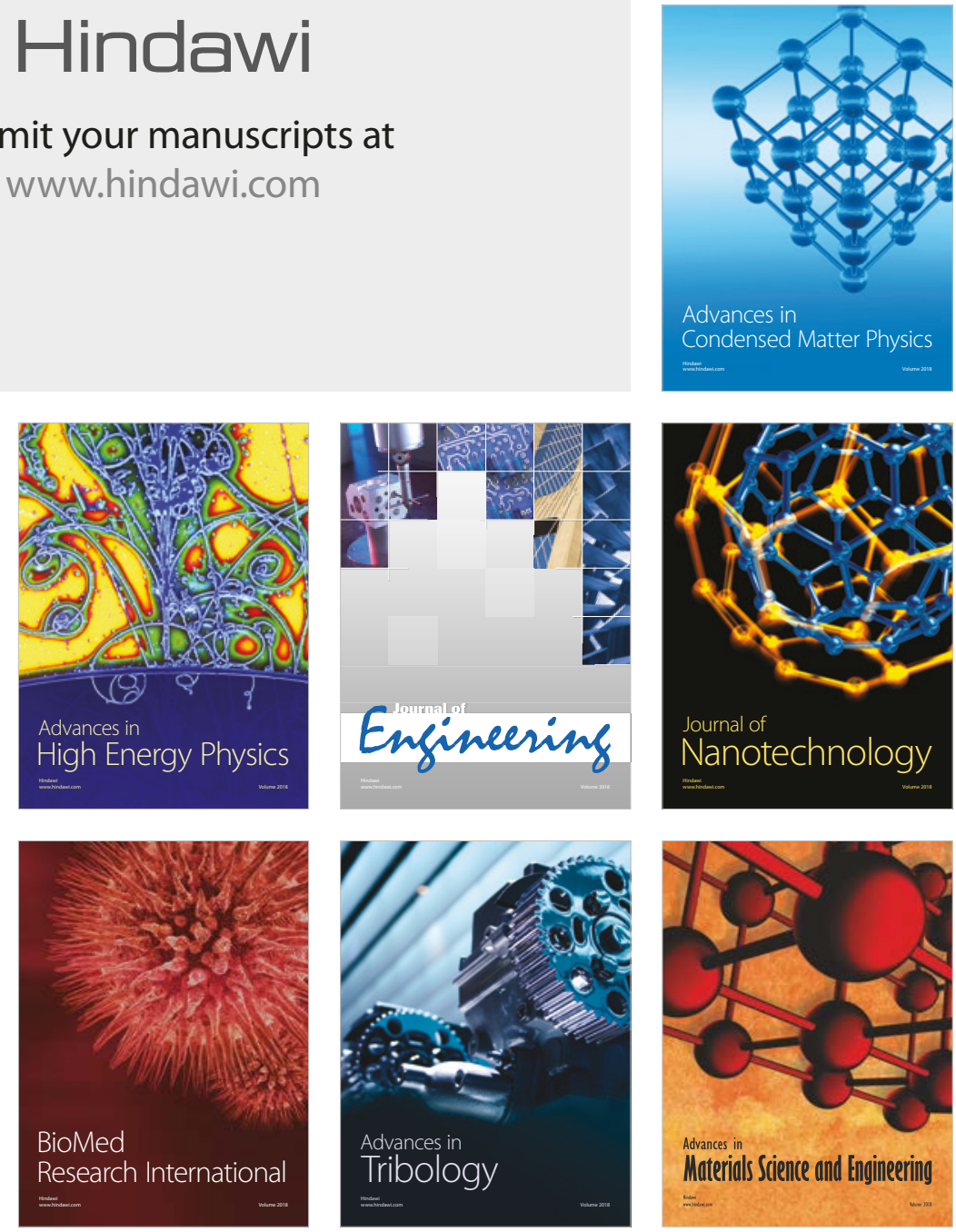